\title{
Association between dietary glycaemic load and selected demographic, socio-economic and lifestyle factors in a group of adult Poles in Lower Silesia - Results of the PURE Poland Study
}

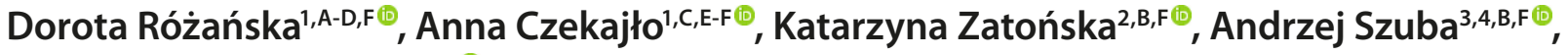 \\ Bożena Regulska-Ilow ${ }^{1, \mathrm{~B}, \mathrm{E}-\mathrm{F} \oplus}$ \\ ${ }^{1}$ Department of Dietetics, Medical University, Wroclaw, Poland \\ ${ }^{2}$ Department of Social Medicine, Medical University, Wroclaw, Poland \\ ${ }^{3}$ Department of Angiology, Medical University, Wroclaw, Poland \\ ${ }^{4}$ Department of Internal Medicine, 4th Military Hospital, Wroclaw, Poland \\ A - Research concept and design, B - Collection and/or assembly of data, C - Data analysis and interpretation, \\ $D$ - Writing the article, E - Critical revision of the article, F - Final approval of article
}

\begin{abstract}
Różańska D, Czekajło A, Zatońska K, Szuba A, Regulska-llow B. Association between dietary glycaemic load and selected demographic, socio-economic and lifestyle factors in a group of adult Poles in Lower Silesia - Results of the PURE Poland Study. Ann Agric Environ Med. 2020; 27(1): 49-55. doi: 10.26444/aaem/105128
\end{abstract}

\begin{abstract}
Introduction. There is a strong association between the occurrence of cardiovascular disease (CVD) and low socioeconomic status (SES). It is interesting to consider whether high dietary glycaemic load (GL) is also associated with low SES or demographic factors.

Objective. The aim of the study is to assess the relationship between dietary GL and demographic, socio-economic and lifestyle factors in a selected population of Polish adults in Lower Silesia.

Materials and method. The study group consisted of 2,025 Polish adults (aged 35-70 years), enrolled in the $1^{\text {st }}$ stage of the Prospective Urban Rural Epidemiological (PURE) study. Nutritional data were collected using a food frequency questionnaire (FFQ), which was developed and validated for the Polish population in Lower Silesia. The overall GL of each diet was computed as a sum of GL values of consumed foods.

Results. Significantly higher GL and GL/1,000 kcal were observed in the diets of males compared to females and in the diets of rural compared to urban inhabitants. An adverse relationship between both $\mathrm{GL}$ and $\mathrm{GL} / 1,000 \mathrm{kcal}$ and level of education was found. The percentage of females, urban inhabitants, people with university education and not married decreased with quartiles of the overall dietary $\mathrm{GL}$ and $\mathrm{GL} / 1,000 \mathrm{kcal}$. The percentage of former smokers, people who never used alcohol and people with low and moderate physical activity decreased with quartiles of GL and GL/1,000 kcal. Lower percentage of individuals aged 44-64 years was observed with quartiles of the overall dietary GL.

Conclusions. Factors such as: male gender, rural place of residence, low level of education and smoking determine the group of people that is the most exposed on the effects of improper nutrition, according to the low quality and/or high amount of carbohydrates defined by GL and GL per 1,000 kcal.
\end{abstract}

Key words

glycaemic load, carbohydrates, cardiovascular disease, socio-economic status, lifestyle

\section{INTRODUCTION}

Cardiovascular disease (CVD) is one of the major cause of death worldwide. In Poland in 2015, total deaths amounted to 102.7 per 10,000 population and CVD accounted for $45.7 \%$ of all deaths [1]. It is well established that low birth weight is a risk factor for insulin resistance, diabetes, dyslipidaemia or hypertension during the life-course, which increases the risk of CVD development [2]. Nonetheless, this risk may be additionally affected by modified lifestyle factors (such as unhealthy diet, sedentary lifestyle, smoking, alcohol consumption) or socio-economic status (SES) during life-

Address for correspondence: Anna Czekajło, Department of Dietetics, Wroclaw Medical University. Poland

E-mail: anna.czekajlo@umed.wroc.pl

Received: 08.11.2018; accepted: 20.02.2019; first published: 22.03.2019 course [3]. Based on a review of the literature, Kaplan and Keil [4] and Glymour [2] described in details why factors associated with low SES can be related to cardiovascular health. In the 10-year follow-up observation a consistent reverse relation between the socio-economic status and the incidence of CVD was observed [5]. Other authors found that 10 -year risk of developing CVD increased significantly with age, and was higher among people with a low level of education and in households with low income [6]. An increased risk of myocardial infarction and coronary heart disease among residents from low socio-economic neighbourhoods was found by Carlsson et al [7]. In a study conducted in a randomly selected Polish population, higher socio-economic status was related to a decreased risk of CVD [8]. In Poland, differences in CVD mortality also depend on place of residence. In 2015, CVD accounted 
for $48.2 \%$ of all deaths in rural and $44.1 \%$ in urban areas [1]. In Poland, in rural compared to urban areas, there is a higher percentage of poverty and registered unemployment which may affect these differences $[9,10]$. Moreover the proportion of income spent on food is higher (even if the absolute expenditure on food is lower) in rural than urban households, which may also be a result of the differences in income between these communities [11]. However Glymour et al. [2] described that not only individual and community factors, but also national socio-economic conditions may independently predict the development of conventional risk factors and CVD.

One of the most important modifiable CVD risk factors is unhealthy diet. There are many determinants that are used to describe the quality of the diet in the context of its role in the development of CVD, e.g. energy intake from proteins, carbohydrates, fats and fatty acids, or dietary intake of selected nutrients, including cholesterol, dietary fibre and antioxidant vitamins. In recent years, also dietary glycaemic load (GL) has been considered an important factor associated with the development of CVD. Glycaemic load is calculated based on the glycaemic index (GI) of food and the available carbohydrate content in the portion of the consumed food [12]. Results of many studies have proved that high dietary GL may increase the risk of CVD $[13,14,15]$.

Due to the strong association between the occurrence of CVD, low SES and demographic factors, it is interesting to consider whether high dietary GL, as a diet quality predictor, may by also associated with these factors.

\section{OBJECTIVE}

The aim of the study is to assess the relationship between dietary glycaemic load and selected demographic, socioeconomic and lifestyle factors in a selected population of Polish adults in Lower Silesia.

\section{MATERIALS AND METHOD}

The study group consisted of Polish adults who participated in the $1^{\text {st }}$ stage of the Prospective Urban Rural Epidemiological (PURE) study, which was conducted in a group of individuals aged 35-70 years from 17 low-income, middle-income, and high-income counties. The main objective of the PURE study was to examine the relationship between social influences and the prevalence of risk factors and chronic non-communicable diseases. A detailed description of the PURE study has been published previously $[16,17]$.

The first stage of the Polish arm of the PURE study was conducted between 2007-2009. Individuals were recruited to the study through radio and television announcements. The participants were volunteers who met the inclusion criteria: age 35-70 years, permanent place of residence in Wroclaw or surrounding villages located in Lower Silesia, and daily energy intake 500-4000 kcal. Among the 2,025 individuals recruited to the study females accounted for $63.0 \%$, urban inhabitants $-59.3 \%$, people who were married $-74.3 \%$, while people with university or secondary education $-29.8 \%$ and $39.3 \%$, respectively. The mean age in the study group was $54.5 \pm 9.8$ years (females $54.6 \pm 9.7$ years, males $54.3 \pm 10.0$ years). All volunteers signed an informed consent form at the beginning of the study. The study was approved by the Polish Ethics Committee (No. KB-443/2006, No. KB-566/2017).

Nutritional data were collected using a food frequency questionnaire (FFQ), which was developed and validated for the population of Lower Silesia from the Polish section of the PURE study [18]. The FFQ included 154 typical products and dishes consumed in Poland and the nutritional value of the diets was computed using the Polish "Food Composition Tables" [19]. A detailed description of the FFQ analysis has been published previously [20].

The total GL of each diet was computed as a sum of GL values of consumed food. Glycaemic load of food product was estimated based on the digestible carbohydrate content in the individual portion and the GI values of this product, according to the following formula: GL = [digestible carbohydrate content in the portion of food $(\mathrm{g}) \times \mathrm{GI}] / 100$. Data of digestible carbohydrate content in food were taken from the "Food Composition Tables" [19]. Data of the GI values of foods were taken from the international tables because there is no such Polish database [21, 22, 23]. The GL values of typical Polish dishes which do not exist in international tables were calculated using recipes described in the "Food Composition Tables" [19]. As dietary GL strongly depends not only on the content of carbohydrate in the diet, but also on the energy intake, both the overall dietary GL and GL per $1,000 \mathrm{kcal}$ were assessed. Although there are many factors that can influence the glycaemic response in each individual, such as meal composition, culinary techniques or individual metabolism, the methodology of the estimation of dietary GL in epidemiological studies is based on the tabular data.

Demographic factors included: gender, age ( $\leq 44$-years old, 45-64-years old and $>64$ years old), place of residence (urban, rural), marital status (currently married vs. others: never married, divorced, widowed, living with partner or separated). Among the socio-economic factors discussed in this study is included the level of education (elemenary/ unknown, trade, secondary/high school or university). Lifestyle factors assessed were: smoking status (never smoked, formerly smoked, current smoker), alcohol consumption (never drank, former drinker, current drinker) and physical activity (PA) level (low <600 MET-minutes/week, moderate 600-3,000 MET-minutes/week, high >3,000 MET-minutes/ week). PA level was calculated using the International Physical Activity Questionnaire (IPAQ).

Statistical analysis. Relationship between the overall dietary GL and GL/1,000 kcal and nutrient content in the diets of the study group was assessed with Spearman's rank correlation. To examine differences in the overall dietary GL and $\mathrm{GL} / 1,000 \mathrm{kcal}$ according to demographic, socio-economic and lifestyle factors, analysis of covariance (ANCOVA) adjusted for potential confounding variables was used. Potential confounders were: gender, age, place of residence, body mass index (BMI) and energy intake (only in the case of overall dietary GL). Relationships between the quartiles of the dietary GL and GL/1,000 kcal and demographic, socioeconomic and lifestyle factors in the study population were assessed with the Chi-square test for trend. Statistical analysis were performed using Statistica software version 12.0 PL (Statsoft Inc., USA). The level of statistical significance was set at $\alpha=0.05$. 


\section{RESULTS}

Correlation between the overall dietary GL and GL/1,000 $\mathrm{kcal}$ and nutrient content in the diets of the study group is presented in Table 1 . There was a strong correlation between the overall dietary GL and daily energy intake ( $\mathrm{r}=0.88)$, as well as the intake of carbohydrates $(\mathrm{r}=0.92)$, total sugars $(\mathrm{r}=0.76)$, protein $(\mathrm{r}=0.74)$, fats $(\mathrm{r}=0.70)$ and dietary fibre $(\mathrm{r}=0.67)$. For $\mathrm{GL} / 1,000 \mathrm{kcal}$, a strong positive correlation was observed only with the percentage of energy from carbohydrates $(r=0.68)$, while moderate negative correlation was observed with the percentage of energy from fats $(\mathrm{r}=-0.54)$ and protein $(\mathrm{r}=-0.42)$.

Table 2 shows the association between dietary GL and GL/1,000 kcal and demographic, socioeconomic and lifestyle factors adjusted for the confounding variables. Significantly

Table 1. Correlation between overall dietary glycaemic load and glycaemic load per 1,000 kcal and nutrient content in the diets of the study group

\begin{tabular}{|c|c|c|c|c|c|}
\hline \multirow{2}{*}{ Nutrient } & Q1 & Q2 & Q3 & Q4 & \multirow{2}{*}{$r^{*}$} \\
\hline & \multicolumn{4}{|c|}{ Overall GL } & \\
\hline $\mathrm{GL}$ & $69.5 \pm 15.0$ & $106.2 \pm 9.2$ & $138.4 \pm 10.3$ & $194.6 \pm 37.4$ & - \\
\hline Energy (kcal) & $1297.5 \pm 289.4$ & $1811.7 \pm 302.3$ & $2252.0 \pm 339.4$ & $3003.9 \pm 669.7$ & 0.88 \\
\hline Protein (g) & $51.6 \pm 15.2$ & $69.5 \pm 17.7$ & $83.9 \pm 18.6$ & $108.7 \pm 31.6$ & 0.74 \\
\hline Protein (\% E) & $15.9 \pm 2.5$ & $15.2 \pm 2.1$ & $14.8 \pm 1.7$ & $14.4 \pm 1.9$ & -0.24 \\
\hline Fats (g) & $47.8 \pm 16.4$ & $64.8 \pm 20.3$ & $82.4 \pm 24.3$ & $106.9 \pm 33.3$ & 0.70 \\
\hline Carbohydrates (g) & $169.7 \pm 36.9$ & $244.0 \pm 30.4$ & $301.3 \pm 36.0$ & $412.6 \pm 87.4$ & 0.92 \\
\hline Carbohydrates (\% E) & $49.6 \pm 6.8$ & $51.4 \pm 6.3$ & $51.2 \pm 5.9$ & $52.5 \pm 5.5$ & 0.14 \\
\hline Fibre (g) & $20.9 \pm 6.7$ & $28.6 \pm 7.7$ & $33.2 \pm 9.1$ & $43.7 \pm 14.7$ & 0.67 \\
\hline \multirow[t]{2}{*}{ Sugar total (g) } & $55.6 \pm 19.6$ & $78.9 \pm 23.1$ & $99.3 \pm 25.6$ & $143.4 \pm 45.2$ & 0.76 \\
\hline & \multicolumn{4}{|c|}{$\mathrm{GL} / 1,000 \mathrm{kcal}$} & \\
\hline GL/1,000 kcal & $48.5 \pm 4.6$ & $57.4 \pm 1.9$ & $63.7 \pm 1.9$ & $72.6 \pm 4.8$ & - \\
\hline Protein $(\mathrm{g})$ & $80.5 \pm 32.8$ & $81.0 \pm 31.9$ & $79.5 \pm 29.9$ & $72.7 \pm 24.4$ & -0.08 \\
\hline Protein (\% E) & $16.4 \pm 2.4$ & $15.3 \pm 1.9$ & $14.6 \pm 1.7$ & $13.9 \pm 1.6$ & -0.42 \\
\hline Fats (g) & $80.9 \pm 36.2$ & $79.5 \pm 35.8$ & $75.9 \pm 30.6$ & $65.5 \pm 24.9$ & -0.15 \\
\hline Fats (\% E) & $36.4 \pm 5.5$ & $33.1 \pm 5.0$ & $31.0 \pm 4.4$ & $27.9 \pm 4.2$ & -0.54 \\
\hline Carbohydrates (g) & $236.4 \pm 92.2$ & $278.2 \pm 102.0$ & $302.2 \pm 104.0$ & $310.7 \pm 97.6$ & 0.30 \\
\hline Carbohydrates (\% E) & $45.3 \pm 4.9$ & $49.9 \pm 4.7$ & $52.8 \pm 4.4$ & $56.7 \pm 4.5$ & 0.68 \\
\hline Fibre (g) & $29.4 \pm 12.2$ & $32.4 \pm 13.5$ & $33.0 \pm 13.5$ & $31.6 \pm 12.5$ & 0.08 \\
\hline Sugar total (g) & $76.8 \pm 37.9$ & $92.9 \pm 42.9$ & $102.6 \pm 46.7$ & $104.7 \pm 42.9$ & 0.26 \\
\hline
\end{tabular}

GL - glycaemic load; Q1,2,3,4 - quartiles 1,2,3,4; \% - percent of energy; ${ }^{*}$ - Spearman's rank correlation coefficient - bold values are statistically significant

Table 2. Association between overall dietary $\mathrm{GL}$ and $\mathrm{GL} / 1,000 \mathrm{kcal}$ and demographic, socio-economic and lifestyle factors in the study group

$\mathrm{p} \quad \mathrm{GL} / 1,000 \mathrm{kcal}$ $\mathrm{X}(95 \% \mathrm{Cl})$
Socio-economic and lifestyle factors

$$
\mathrm{GL}
$$

$X(95 \% \mathrm{Cl})$
$\mathrm{P}$

0.0129 $60.1(59.6-60.7)$ $61.2(60.2-62.2)$

Age

$129.0(127.6-130.4)$

$126.6(125.5-127.6)$

0.0077

$128.9(127.8-129.9)$

$129.1(127.0-131.3)$

$>64$ y.o. $(n=322)$

Place of residence Urban $(n=1200)$ Rural ( $n=825$ )

$126.9(125.8-128.0)$

$131.9(130.5-133.2)$

$<0.0001$ Elementary/unknown $(\mathrm{n}=302) \quad 132.2(129.7-134.6)$

Trade $(\mathrm{n}=324) \quad 130.5(128.3-132.8)$

Education level

Secondary/high school $(n=796)$

$128.8(127.4-130.2)$

$126.9(125.1-128.8)$

Marital status

Married $(n=1504)$ Others* $(\mathrm{n}=521)$

$125.7(124.6-126.7)$

$124.8(123.1-126.5)$

Never used $(n=957)$

Smoking status

Formely used $(n=643)$

Currently uses $(n=425)$

Never used $(n=452)$

Formely used $(n=207)$

Currently uses ( $n=1366)$

Low and moderate $(n=574)$ High ( $n=1293)$

$126.2(124.7-127.8)$

$127.2(125.3-129.1)$

130.8 (128.9-132.6)

Alcohol consumption

$129.4(126.7-132.1)$

$128.0(126.9-129.1)$

Physical activity

$123.5(121.9-125.1)$

$124.2(123.1-125.3)$
$62.4(61.3-63.6)$

$61.4(60.4-62.5)$ $60.6(59.9-61.3)$ $59.6(58.7-60.4)$ $60.6(60.1-61.1)$ $60.0(59.2-60.8)$ $60.9(60.3-61.5)$ $60.3(59.6-61.0)$ $60.6(59.7-61.5)$ $61.7(60.8-62.5)$ $60.7(59.5-62.0)$ $60.3(59.8-60.9)$ $60.0(59.2-60.7)$ $60.5(60.0-61.0)$
$60.6(60.1-61.1) \quad$ Ns

Ns $59.3(58.8-59.9)$ $62.3(61.7-63.0)$

0.0001

0.0038

Ns

Ns

0.0422

Ns

GL - glyceamic load; X (95\% Cl) - mean ( $95 \%$ confidence interval); Ns - no statistically significant difference; ${ }^{*}$ never married, divorced, widowed, living with partner or separated 
higher GL and GL/1,000 kcal were observed in the diets of females compared to males and in the diets of rural compared to urban inhabitants. An adverse relationship between both GL and GL/1,000 kcal and level of education was found. There was also a significant relationship between alcohol consumption and glycaemic load of a diet. No significant differences between GL and GL/1,000 kcal and other studied factors were observed.

Tables 3 and 4 show the relationship between the overall dietary GL and GL/1,000 kcal and demographic, socioeconomic and lifestyle factors in the study population. The percentage of females, urban inhabitants, people with university education and not married decreased with quartiles of the overall dietary GL and GL/1,000 kcal. Lower percentage of former smokers, people who never drank alcohol and people with low and moderate physical activity level was also observed with an increase of both GL and GL/1,000 kcal quartiles. Moreover, a lower percentage of individuals aged 44-64 years was observed with an increase of the overall dietary GL quartiles.

\section{DISCUSSION}

The presented study assesses the relationship between dietary glycaemic load and selected demographic, socioeconomic and lifestyle factors in the group of Lower Silesia inhabitants. Glycaemic load is one of the parameters that can be used to describe the quality of the diet in view of its importance in maintaining health. The results of numerous studies have shown that high GI and/or high GL diets may increase the risk of type 2 diabetes [24], cardiovascular disease [13, 14, 15], metabolic syndrome [25] and cancer [26, 27] development. On the other hand, many authors have proved that higher diet quality was associated with higher socio-economic status, including such determinants as: income, working status, marital status, and level of education [28, 29, 30, 31]. A previous study conducted in Poland also showed a relationship between gender, age and level of education, and the nutritional value of the diets [32].

Dietary glycaemic load is a value that strongly correlates with the energy and macronutrient intake and therefore many authors propose to adjust GL for total energy intake [26, 23-37]. However some authors discuss the results of their studies only with reference to the overall dietary glycaemic load $[38,39]$. The current study presents the relationships

Table 3. Relationship between overall dietary glycaemic load and demographic, socio-economic and lifestyle factors in the study population

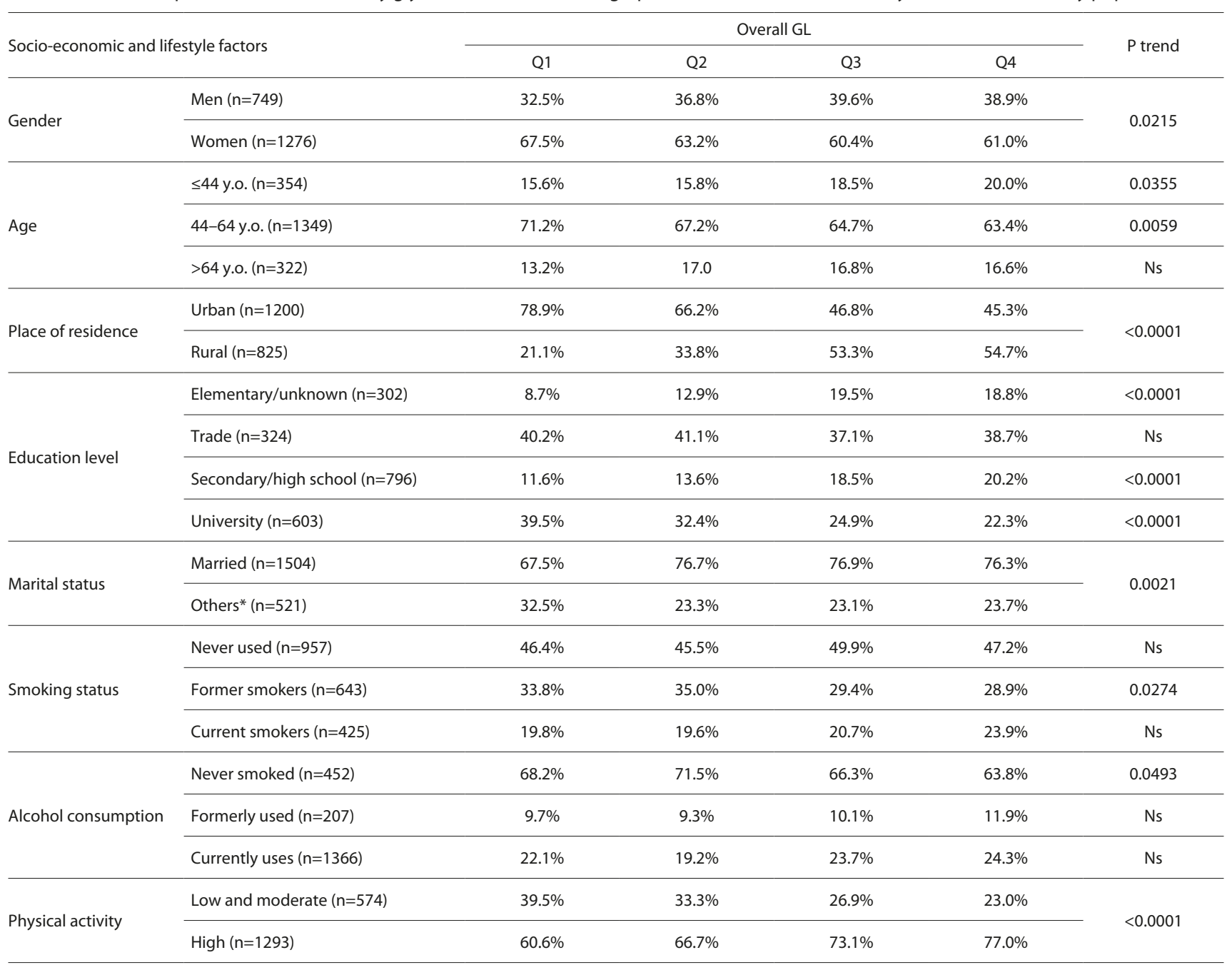

GL - glycaemic load; $\mathrm{Q} 1,2,3,4$ - quartiles 1,2,3,4; Ns - no statistically significant difference * never married, divorced, widowed, living with partner or separated 
Table 4. Relationship between dietary glycaemic load per 1,000 kcal and demographic, socio-economic and lifestyle factors in the study population

\begin{tabular}{|c|c|c|c|c|c|c|}
\hline \multirow{2}{*}{\multicolumn{2}{|c|}{ Socio-economic and lifestyle factors }} & \multicolumn{4}{|c|}{$\mathrm{GL} / 1,000 \mathrm{kcal}$} & \multirow{2}{*}{$P$ trend } \\
\hline & & \multirow{2}{*}{$\frac{\text { Q1 }}{34.7 \%}$} & \multirow{2}{*}{$\begin{array}{c}\text { Q2 } \\
36.0 \%\end{array}$} & \multirow{2}{*}{$\frac{\text { Q3 }}{34.6 \%}$} & \multirow{2}{*}{$\begin{array}{c}\text { Q4 } \\
42.6 \%\end{array}$} & \\
\hline & Men $(n=749)$ & & & & & \multirow{2}{*}{0.0201} \\
\hline Genaer & Women $(n=1276)$ & $65.3 \%$ & $64.0 \%$ & $65.4 \%$ & $57.4 \%$ & \\
\hline \multirow{3}{*}{ Age } & $\leq 44$ y.o. $(n=354)$ & $16.6 \%$ & $13.4 \%$ & $20.8 \%$ & $19.1 \%$ & 0.0468 \\
\hline & $44-64$ y.o. $(n=1349)$ & $67.5 \%$ & $68.6 \%$ & $66.2 \%$ & $64.3 \%$ & Ns \\
\hline & $>64$ y.o. $(n=322)$ & $16.0 \%$ & $18.0 \%$ & $13.0 \%$ & $16.6 \%$ & Ns \\
\hline \multirow{2}{*}{ Place of residence } & Urban $(n=1200)$ & $71.2 \%$ & $60.5 \%$ & $52.0 \%$ & $53.5 \%$ & \multirow{2}{*}{$<0.0001$} \\
\hline & Rural ( $n=825)$ & $28.8 \%$ & $39.5 \%$ & $48.0 \%$ & $46.6 \%$ & \\
\hline \multirow{3}{*}{ Education level } & Elementary/unknown $(n=302)$ & $10.5 \%$ & $15.0 \%$ & $15.6 \%$ & $18.7 \%$ & 0.0003 \\
\hline & Trade $(n=324)$ & $42.6 \%$ & $39.7 \%$ & $37.9 \%$ & $36.9 \%$ & Ns \\
\hline & Secondary/high school (n=796) & $12.2 \%$ & $13.4 \%$ & $19.4 \%$ & $18.9 \%$ & 0.0003 \\
\hline \multirow{2}{*}{ Marital status } & Married (n=1504) & $71.2 \%$ & $73.7 \%$ & $73.5 \%$ & $78.9 \%$ & \multirow{2}{*}{0.0079} \\
\hline & Others* $(n=521)$ & $28.9 \%$ & $26.3 \%$ & $26.5 \%$ & $21.1 \%$ & \\
\hline \multirow{3}{*}{ Smoking status } & Never smoked $(n=957)$ & $44.4 \%$ & $47.2 \%$ & $52.3 \%$ & $45.2 \%$ & Ns \\
\hline & Formerly smoked $(n=643)$ & $35.5 \%$ & $35.4 \%$ & $25.7 \%$ & $30.4 \%$ & 0.0069 \\
\hline & Currently uses $(n=425)$ & $20.1 \%$ & $17.4 \%$ & $22.0 \%$ & $24.5 \%$ & 0.0296 \\
\hline \multirow{3}{*}{ Alcohol consumption } & Never smoked $(n=452)$ & $71.4 \%$ & $67.8 \%$ & $65.0 \%$ & $65.7 \%$ & 0.0317 \\
\hline & Formely used ( $n=207$ ) & $9.9 \%$ & $9.9 \%$ & $9.5 \%$ & $11.6 \%$ & Ns \\
\hline & Currently uses ( $n=1366)$ & $18.7 \%$ & $22.3 \%$ & $25.5 \%$ & $22.7 \%$ & Ns \\
\hline \multirow{2}{*}{ Physical activity } & Low and moderate $(n=574)$ & $36.9 \%$ & $31.2 \%$ & $26.3 \%$ & $28.4 \%$ & \multirow{2}{*}{0.0014} \\
\hline & High $(n=1293)$ & $63.1 \%$ & $68.8 \%$ & $73.7 \%$ & $71.6 \%$ & \\
\hline
\end{tabular}

GL - glycaemic load; Q1,2,3,4 - quartiles 1,2,3,4; Ns - no statistically significant difference

* never married, divorced, widowed, living with partner or separated;

between demographic, socio-economic and selected lifestyle factors and both the overall GL and GL per 1,000 kcal.

In the studied group of Polish adults, higher GL and $\mathrm{GL} / 1,000 \mathrm{kcal}$ were noted in the diets of females compared to males and in the diets of rural compared to urban dwellers. The percentage of females and urban inhabitants decreased with quartiles of dietary GL. Based on the data from the Central Statistical Office in Poland, the average monthly consumption of carbohydrate food products per capita in 2010 was much higher in households of farmers than in the overall population [40]. Bread and cereal consumption amounted to $8.48 \mathrm{~kg}$ in households of farmers while in the overall population $-7.05 \mathrm{~kg}$. The average monthly consumption of potatoes amounted to 7.10 and $4.88 \mathrm{~kg}$ per capita, respectively. Moreover, the average monthly consumption of sugar, jam, honey, chocolate and confectionery was also higher in households of farmers (2.35 kg per capita) than in the overall population (1.77 kg per capita). The results of the current study appear to be consistent with these observations. Although the differences in food consumption between rural and urban communities in Poland decreased in recent years they still remain noticeable. Rural inhabitants compared to urban consumed more grains, potatoes, sugar, honey and sweets [11]. These are products that may affect the dietary GL the most, because they are usually the main source of carbohydrates in the daily diet.

In the study group, the percentage of individuals aged 4464 years decreased with quartiles of the overall dietary GL and the percentage of individuals aged $\leq 44$ years increased with quartiles of the overall GL and GL/1,000 kcal. Other authors observed different relationships between age and dietary glycaemic load. In the study conducted by Krishnan et al. [35], the youngest participants of the Black Females's Health Study were in the $5^{\text {th }}$ quintile of energy-adjusted GL. De la Fuente-Arrillaga [39] found that the youngest participants of the SUN project were in the $4^{\text {th }}$ quintile of GL $\left(36.8 \pm 11.3\right.$ years) and the oldest were in $1^{\text {st }}$ quintile $(39.4 \pm 11.5$ years). In the Health, Aging, and Body Composition Study conducted among adults aged 70-79 years the opposite association between age and GL was found [34].

The results of the presented study show an adverse relationship between both GL and GL/1,000 kcal and the level of education in the inhabitants of Lower Silesia. The percentage of individuals with university education decreased with quartiles of the overall dietary GL and GL/1,000 kcal. Levitan et al. [33] in the group of Swedish females (45 - 79-years-old) also found that higher energy-adjusted dietary GL was more characteristic of those with lower than high school education level. Sahyoun et al. [34] conducted a prospective cohort study among 3,075 adults aged 70 - 79-years-old and observed a lowered percentage of people who completed high school with an increase of energy-adjusted GL quintiles. Sieri et al. [36], however, observed a higher percentage of females and males with education length $\geq 8$ years with an increase of energy-adjusted GL (quartile $1^{\text {st }}$ vs. $4^{\text {th }}: 40.6 \%$ vs. $46.2 \%$ and $49.8 \%$ vs. $53.5 \%$, respectively).

In the current study, higher GL/1,000 kcal was associated with a higher percentage of current smokers and with a lower percentage of people who never drank alcohol. Other authors observed different relationships between GL and smoking. In the SUN project, higher GL was associated with lower percentage of current and ex-smokers [39]. Levitan 
et al. [33] also observed a lower percentage of current and past smokers with the quartiles of energy-adjusted dietary GL. On the other hand, higher energy-adjusted GL was associated with a higher percentage of those who never smoked [33]. Krishnan et al. [35] observed a higher percentage of people who smoked $\geq 15$ cigarettes/day in the $1^{\text {st }}$ quintile of energy-adjusted GL. Taking into account the association between alcohol consumption and dietary GL, the results are similar between authors. Levitan et al. [33] in a group of Swedish females observed lower alcohol intake (g/day) with increasing energy-adjusted dietary GL. Sahyoun et al. [34] observed a lower percentage of people who declared any alcohol consumption with higher energy-adjusted GL. Also in the study conducted by Krishnan et al. [35], a lower percentage of people who consumed $\geq 7$ drinks/week was associated with higher energy-adjusted GL. In the EPICOR study higher energy-adjusted GL was associated with lower percentage of females and males who consumed $>24 \mathrm{~g}$ of alcohol/day, and with higher percentage of abstainers [36]. In the SUN project, there was no statistically significant association between mean daily alcohol intake and GL [39].

This study shows a relationship between dietary GL and selected demographic, socio-economic and lifestyle factors in a group of Lower Silesia inhabitants. However, dietary habits, as a component of a lifestyle, are the only aspect that can be related to the socio-economic factors. Higher SES, commonly understood as a higher education level and income, is associated with higher earnings which can be spent for better healthcare or healthier food. The financial aspect is not the only reason why the SES is associated with CVD risk. Socio-economic inequalities in health status can be also explained by the behavioural differences. Another important mechanism is that SES is associated with psychological factors. Psychological stressors (e.g. social position, life stress, poor working or living conditions) affect the functioning of the body, causing anxiety or depression. This may activate the sympathetic nervous system and hypothalamic-pituitaryadrenal axis what leads to platelet activation, endothelial dysfunction, hypertension, or even inflammation and modification in the cardiac cellular electrophysiology [4].

Limitations and strengths of the study. The participants were recruited from the province of Lower Silesia through radio and television; therefore the studied group was not a representative sample. Nevertheless, the strength is that the study was conducted in a large group of more than 2,000 subjects. The question about income which would describe more precisely the SES was not included. However, the study was performed using standardized methods and a region-specific food frequency questionnaire of good quality validated for this study group. The FFQ were collected by a trained staff. FFQ is a simple, cost-effective and timesaving method for assessment of the usual dietary intake. All dietary assessment methods based on dietary records or questionnaires have advantages and disadvantages; however, the FFQ validated for the study population is the most commonly used and suitable method in nutrition epidemiology worldwide.

\section{CONCLUSIONS}

Based on the results of the presented study, it can be summarized that factors such as: male gender, rural place of residence, low level of education and smoking determine the group of people most exposed to the effects of improper nutrition, according to the low quality and/or high intake of carbohydrates defined by GL and GL per 1,000 kcal. This group of people should be covered by medical care and receive nutritional education about the proper selection of products that are the sources of carbohydrates and other nutrients in the diet. It appears that posters presenting principal nutrition recommendations, i.e. Food Pyramid, might be hung in the waiting rooms in healthcare clinics, and each patient who comes to the clinic should receive a booklet about proper nutrition, prepared previously by a qualified dietician. General practitioners should always emphasize that noncommunicable disease are related to unhealthy diet, and when necessary they should suggest a dietary consultation. Moreover, in order to minimize the differences in sociodemographic factors in the future and increase the awareness of the relationship between diet and health in the population, it is recommended that nutrition education should be started very early, even among children in kindergartens.

\section{REFERENCES}

1. Rozkrut D and the Editorial Board of the Central Statistical Office. Demographic Yearbook of Poland. Central Statistical Office, Warsaw 2017, pp. 324-327.

2. Glymour MM, Clark ChR, Patton KK. Socioeconomic determinants of cardiovascular disease: recent findings and future directions. Curr Epidemiol Rep. 2014; 1: 89-97.

3. Piepoli MF, Hoes AW, Agewall S, Albus C, Brotons C, Catapano AL, et al. Authors/Task Force Members. 2016 European Guidelines on cardiovascular disease prevention in clinical practice. Eur Heart J. 2016; 37(29): 2315-2381.

4. Kaplan GA, Keil JE. Socioeconomic factors and cardiovascular disease: a review of the literature. Circulation 1993; 88: 1973-1998.

5. Kollia N, Panagiotakos DB, Georgousopoulou E, Chrysohoou C, Tousoulis D, Stefanadis C, et al. Exploring the association between low socioeconomic status and cardiovascular disease risk in healthy Greeks, in the years of financial crisis (2002-2012): The ATTICA study. Int J Cardiol. 2016; 223: 758-763.

6. Yang Q, Zhong Y, Ritchey M, Loustalot F, Hong Y, Merritt R, et al. Predicted 10-year risk of developing cardiovascular disease at the state level in the U.S. Am J Prev Med. 2015; 48(1): 58-69.

7. Carlsson AC, Li X, Holzmann MJ, Wändell P, Gasevic D, Sundquist J, et al. Neighbourhood socioeconomic status and coronary heart disease in individuals between 40 and 50 years. Heart. 2016; 102(10): 775-782.

8. Kozakiewicz K, Podolecka E, Kwaśniewska M, Drygas W, Pająk A, Tendera M. Association between socioeconomic status and cardiovascular risk. Kardiol Pol. 2016; 74(2): 179-184.

9. Statistical Bulletin of Dolnośląskie Voivodship. Statistical Office in Wroclaw. Wroclaw 2009, pp. 73

10. Zasięg ubóstwa ekonomicznego w Polsce w 2017 r. Central Statistical Office in Poland. https://stat.gov.pl/files/gfx/portalinformacyjny/pl/ defaultaktualnosci/5487/14/5/1/zasieg_ubostwa_ekonomicznego_w_ polsce_w_2017.pdf

11. Łyson P and the Editorial Board of the Central Statistical Office. Socio-economic situation of households in 2000-2015 urban-rural diversity. Central Statistical Office in Poland, Social Surveys and Living Conditions Departfemalest. Warsaw 2017, pp. 30; pp. 40

12. Venn BJ, Green TJ. Glycemic index and glycemic load: measurefemalest issues and their effect on diet-disease relationships. Eur J Clin Nutr. 2007; 61(Suppl 1): S122-S131.

13. Burger KNJ, Beulens JWJ, Boer JMA, Spijkerman AMW, van der A DL. Dietary glycemic load and glycemic index and risk of coronary heart disease and stroke in Dutch females and females: The EPIC-MORGEN Study. PLoS ONE 2011; 6(10): e25955. doi:10.1371/journal.pone.0025955 
14. Turati F, Dilis V, Rossi M, Lagiou P, Benetou V, Katsoulis M, et al. Glycemic load and coronary heart disease in a Mediterranean population: the EPIC Greek cohort study. Nutr Metab Cardiovasc Dis. $2015 ; 25(3): 336-342$.

15. Yu D, Zhang X, Shu XO, Cai H, Li H, Ding D, et al. Dietary glycemic index, glycemic load, and refined carbohydrates are associated with risk of stroke: a prospective cohort study in urban Chinese females. Am J Clin Nutr. 2016; 104(5): 1345-1351.

16. Corsi DJ, Subramanian SV, Chow CK, McKee M, Chifamba J, Dagenais G, et al. Prospective Urban Rural Epidemiology (PURE) study: baseline characteristics of the household sample and comparative analyses with national data in 17 countries. Am Heart J. 2013; 166(4): 636-646.

17. Teo K, Chow CK, Vaz M, Rangarajan S, Yusuf S. The Prospective Urban Rural Epidemiology (PURE) study: examining the impact of societal influences on chronic noncommunicable diseases in low-, middle-, and high-income countries. Am Heart J. 2009; 158(1): 1-7.

18. Dehghan M, Ilow R, Zatonska K, Szuba A, Zhang X, Femaleste A, et al. Developfemalest, reproducibility and validity of the food frequency questionnaire in the Poland arm of the Prospective Urban and Rural Epidemiological (PURE) study. J Hum Nutr Diet. 2012; 25(3): 225-232.

19. Kunachowicz H, Przygoda B, Irena N, Iwanow K. Food Composition Tables. Warszawa, Wydawnictwo Lekarskie PZWL, 2005 (in Polish).

20. Różańska D, Regulska-Ilow B, Ilow R, Zatońska K, Wołyniec M, Mandecka A, et al. Differences in energy and selected macronutrients intake with diet between females and females from urban and rural areas of the Lower Silesia in Poland: the Polish arm of the Prospective Urban Rural Epidemiological (PURE) study. J Health Inequal. 2016; 2(2): 148-154.

21. Foster-Powell K, Holt SH, Brand-Miller JC. International table of glycemic index and glycemic load values: 2002. Am J Clin Nutr. 2002; 76(1): 5-56.

22. Atkinson FS, Foster-Powell K, Brand-Miller JC. International Tables of Glycemic Index and Glycemic Load Values: 2008. Diabetes Care. 2008; 31(12): 2281-2283.

23. National Cancer Institute, Tables of GI; http://riskfactor.cancer.gov/ DHQ/database/\#gl

24. Bhupathiraju SN, Tobias DK, Malik VS, Pan A, Hruby A, Manson JE, et al. Glycemic index, glycemic load, and risk of type 2 diabetes: results from 3 large US cohorts and an updated meta-analysis. Am J Clin Nutr. 2014; 100(1): 218-232.

25. Juanola-Falgarona M, Salas-Salvadó J, Buil-Cosiales P, Corella D, Estruch R, Ros E, et al. Dietary glycemic index and glycemic load are positively associated with risk of developing metabolic syndrome in middle-aged and elderly adults. J Am Geriatr Soc. 2015; 63(10): 1991-2000.

26. Sieri S, Krogh V, Agnoli C, Ricceri F, Palli D, Masala G, et al. Dietary glycemic index and glycemic load and risk of colorectal cancer: results from the EPIC-Italy study. Int J Cancer. 2015; 136(12): 2923-2931.
27. Xu WH, Xiang YB, Zhang X, Ruan Z, Cai H, Zheng W, et al. Association of dietary glycemic index and glycemic load with endometrial cancer risk among Chinese females. Nutr Cancer. 2015; 67(1): 89-97.

28. Grech A, Sui Z, Siu HY, Zheng M, Allman-Farinelli M, Rangan A. Socioeconomic determinants of diet quality in Australian adults using the validated Healthy Eating Index for Australian Adults (HEIFA-2013). Healthcare (Basel). 2017; 5(1). pii: E7. doi: 10.3390/healthcare5010007.

29. Martin JC, Moran LJ, Teede HJ, Ranasinha S, Lombard CB, Harrison CL. Exploring diet quality between urban and rural dwelling females of reproductive age. Nutrients. 2017; 9(6). pii: E586. doi: 10.3390/ nu9060586.

30. Wang DD, Leung CW, Li Y, Ding EL, Chiuve SE, Hu FB, et al. Trends in dietary quality among adults in the United States, 1999 through 2010. JAMA Intern Med. 2014; 174(10): 1587-1595.

31. Conklin AI, Forouhi NG, Surtees P, Khaw KT, Wareham NJ, Monsivais P. Social relationships and healthful dietary behaviour: evidence from over-50s in the EPIC cohort, UK. Soc Sci Med. 2014; 100: 167-175.

32. Ilow R, Regulska-Ilow B, Różańska D, Zatońska K, Dehghan M, Zhang $\mathrm{X}$, et al. Assessfemalest of dietary intake in a sample of Polish population - baseline assessfemalest from the prospective cohort 'PONS' study. Ann Agric Environ Med. 2011; 18(2): 229-234.

33. Levitan EB, Mittleman MA, Håkansson N, Wolk A. Dietary glycemic index, dietary glycemic load, and cardiovascular disease in middle-aged and older Swedish females. Am J Clin Nutr. 2007; 85(6): 1521-1526.

34. Sahyoun NR, Anderson AL, Tylavsky FA, Lee JS, Sellmeyer DE, Harris TB. Dietary glycemic index and glycemic load and the risk of type 2 diabetes in older adults. Am J Clin Nutr 2008; 87(1): 126-131.

35. Krishnan S, Rosenberg L, Singer M, Hu FB, Djoussé L, Cupples LA, et al. Glycemic index, glycemic load, and cereal fiber intake and risk of type 2 diabetes in US black females. Arch Intern Med. 2007; 167(21): 2304-2309.

36. Sieri S, Krogh V, Berrino F, Evangelista A, Agnoli C, Brighenti F, et al. Dietary glycemic load and index and risk of coronary heart disease in a large Italian cohort. Arch Intern Med. 2010; 170(7): 640-647.

37. Murakami K, Sasaki S. Glycemic index and glycemic load of the diets of Japanese adults: the 2012 National Health and Nutrition Survey, Japan. Nutrition. 2018; 46: 53-61.

38. Anderson C, Milne GL, Park YM, Sandler DP, Nichols HB. Dietary glycemic index and glycemic load are positively associated with oxidative stress among prefemalesopausal females. J Nutr. 2018; 148(1): 125-130.

39. De la Fuente-Arrillaga C, Martinez-Gonzalez MA, Zazpe I, VazquezRuiz Z, Benito-Corchon S, Bes-Rastrollo M. Glycemic load, glycemic index, bread and incidence of overweight/obesity in a Mediterranean cohort: the SUN project. BMC Public Health. 2014; 14: 1091, doi: $10.1186 / 1471-2458-14-1091$

40. Witkowski J, Dmochowska H. and the Editorial Board of the Central Statistical Office. Statistical Yearbook of Agriculture. Central Statistical Office, Warsaw 2014

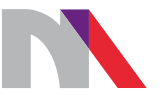

Ministry of Science and Higher Education

Republic of Poland

Generation of the DOI (Digital Object Identifier) - task financed under the agreement No. 618/P-DUN/2019 by the Minister of Science and Higher Education 